\title{
POST-HURRICANE COASTAL MAPPING AND CHANGE ANALYSIS: NATIONAL COASTAL MAPPING PROGRAM
}

Eve Eisemann, United States Army Corps of Engineers, Coastal Hydraulics Laboratory, eve.r.eisemann@usace.army.mil Lauren Dunkin, United States Army Corps of Engineers, Coastal Hydraulics Laboratory, lauren.m.dunkin@usace.army.mil Michael Hartman, United States Army Corps of Engineers, Coastal Hydraulics Laboratory, michael.h.hartman@usace.army.mil

Jennifer Wozencraft, United States Army Corps of Engineers, Coastal Hydraulics Laboratory, jennifer.m.wozencraft

@usace.army.mil

\section{INTRODUCTION}

Hurricane and other extreme storm impacts pose one of the greatest threats to coastal environments, populations, and infrastructure. The U.S. Army Corps of Engineers (USACE) National Coastal Mapping Program (NCMP), executed by the Joint Airborne Lidar Bathymetry Technical Center of Expertise (JALBTCX), collects and processes high resolution aerial imagery and lidar data that provide regional datasets to support assessments of coastal change. The NCMP surveying methods and data products are invaluable tools for coastal management and have the potential to produce rapid-response data following extreme storm impacts. Emergency post-storm deployment of this system was used following Hurricane Matthew's impact in October 2016 where the NCMP surveyed from Key Biscayne, FL to the VA/MD border between October 27th and December 2nd, collecting topographic and bathymetric lidar along the coast in a $1.5 \mathrm{~km}$ swath (Figure 1A). Approximately one year later, Hurricane Irma impacted the Florida east and west coast in September 2017. The NCMP surveyed the entire Florida east coast, including the Keys, in addition to Collier County on the West Coast of Florida from September 22 to October 25 (Figure 1B).

\section{METHODS}

Using a specifically designed JALBTCX volume change toolbox, the Post-Matthew survey was compared with previously collected NCMP data to quantify beach volume, shoreline, and structure change along the coast. Pre-storm datasets utilized ranged in collection date from 2010 in some states (GA and part of SC) to spring 2016 in FL. The Post-Irma volume change analysis utilized the Post-Matthew survey as the before dataset. Parameters were produced for individual shoreperpendicular, $100 \mathrm{~m}$ wide bins along the entire coast. The mean high water (MHW) contour was mapped for both datasets, and a shoreline change rate calculated for each bin. Additionally, volume change was calculated both above and below this contour in each bin. These volume changes are also presented as average volume change per unit area in the bin, average volume change rate within the bin, and volume change rate per foot of shoreline.

\section{DISCUSSION}

The high resolution, regional datasets are valuable for understanding and quantifying the coastal impacts of a hurricane. The effects of Hurricane Matthew on coastal protection and navigation structures can be clearly observed from the volume change data (Figure 1C). Quantification of shoreline change and overall volume change along the coast provides a clear picture of the impact a single storm can have on both natural and manmade areas along the coast. Additionally, the Hurricane Irma dataset provides insight into coastal impacts to a region that is still recovering from a previous extreme storm event. The NCMP data and analysis are invaluable for all states impacted by Hurricane Matthew and Hurricane Irma. The NCMP mapping effort captured specific coastal changes and damage caused by the hurricanes, providing vital information for coastal planning and research within and outside of the USACE.

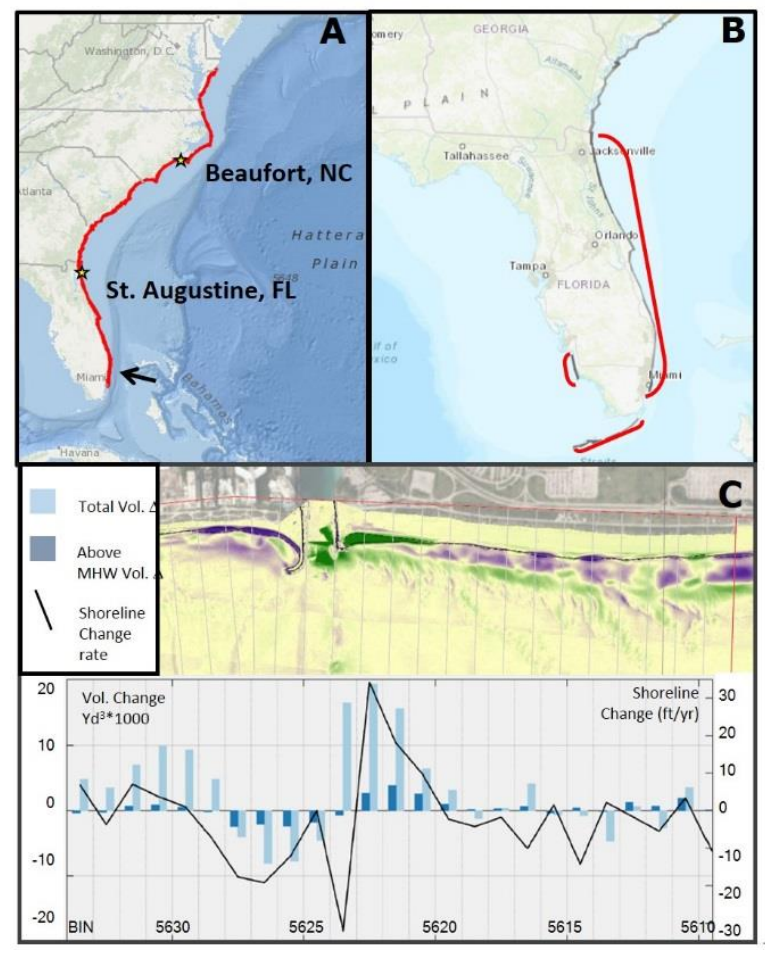

Figure 1. (A) Post-Matthew survey response in 2016 from Key Biscayne, FL to the Virginia/Maryland border. (B) Post-Irma survey response in 2017 for Florida east coast, Keys, and small portion of the west coast of Florida. (C) Elevation change for an example site in Florida following Hurricane Matthew. Volume and shoreline change for individual bins are shown on the graph. Black arrow in A shows location. Dark purple indicates $1.5 \mathrm{~m}$ of erosion and dark green indicates $1.5 \mathrm{~m}$ of deposition. 